\title{
CQ-Type Algorithm for Reckoning Best Proximity Points of EP-Operators
}

\author{
Hassan Houmani ${ }^{1,2, *}$ and Teodor Turcanu ${ }^{1}$ \\ 1 Department of Mathematics and Informatics, University Politehnica of Bucharest, \\ 060042 Bucharest, Romania; deimosted@yahoo.com \\ 2 Lebanese International University-LIU, 146404 Beirut, Lebanon \\ * Correspondence: hassanhoumani@yahoo.com
}

Received: 27 November 2019; Accepted: 15 December 2019; Published: 18 December 2019

\begin{abstract}
We introduce a new class of non-self mappings by means of a condition which is called the (EP)-condition. This class includes proximal generalized nonexpansive mappings. It is shown that the existence of best proximity points for (EP)-mappings is equivalent to the existence of an approximate best proximity point sequence generated by a three-step iterative process. We also construct a CQ-type algorithm which generates a strongly convergent sequence to the best proximity point for a given (EP)-mapping.
\end{abstract}

Keywords: non-self mapping; best proximity point; CQ algorithm

MSC: 47H09; 47H10

\section{Introduction}

The Banach contraction principle, which is the central result of the metric fixed point theory, has for decades been a source of inspiration for many authors. It states that any contraction mapping acting on a complete metric space has a unique fixed point, which is the limit of a sequence obtained by successive iterations of the given mapping. The attempts to extend this fundamental result have generated an impressive amount of scientific papers, as well as new areas of research. For instance, the theory of nonexpansive mappings, which naturally generalizes contraction mappings, has been a central topic during the last five decades. Fundamental existence results for nonexpansive mappings have been obtained by Kirk [1], Browder [2], and Göhde [3]. Later on, even wider classes of mappings were proposed and studied (see for instance Suzuki [4], García-Falset et al. [5]). At the same time, besides Picard's iteration used for contractions, some authors have introduced other iteration schemes (such as Mann [6] and Ishikawa [7]). This was in part due to the fact that Picard's iterative sequence for nonexpansive mappings does not necessarily converge. For more recently introduced iterative schemes, one can see Noor [8], Agrawal et al. [9], Abbas and Nazir, [10], Sintunavarat and Pitea [11], Thakur et al. [12-14], etc.

Another natural extension is to consider non-self mappings between two disjoint sets instead of mappings of a set into itself. In this setting, however, there is no point asking for fixed points, but instead one looks for best proximity points. More precisely, let $T: X \rightarrow Y$ be a mapping between two subsets $X$ and $Y$ of a metric space $E$. A best proximity point $x \in X$ is a point such that $d(x, T x)$ is minimal. The interest for this type of problem was ignited by Fan [15]. Later on, authors such as Reich [16], Seghal and Singh [17], Naraghirad [18], and others have picked up on this subject and extended Fan's result in multiple ways.

The results presented in this paper relate to the above mentioned context as follows. Firstly, we consider the iterative process introduced by Thakur et al. [12] (which we shall call henceforth 
TTP16), but for mappings satisfying the condition (E), introduced by García-Falset et al. [5], extending Lemma 3.1 and, respectively, Theorem 3.2 from [12].

Secondly, we adapt the iterative process TTP16 to the setting of non-self mappings and define a new class of operators which are required to have the (EP)-property (see below). This class includes proximal generalized nonexpansive mappings, introduced by Gabeleh [19]. It is shown that the (EP)-mappings have best proximity points if and only if the iterative sequence generated by the adapted TTP16 process is an approximate best proximity point sequence.

In the last section, we construct an algorithm which is a hybrid between the CQ algorithm of Nakajo and Takahashi [20] (see also Takahashi [21] and Jakob [22]) and the adapted TTP16 iterative process. The motivation in this case being the strong convergence of the sequences generated by the algorithm to best proximity points for (EP)-mappings.

\section{Preliminaries}

Let $X$ and $Y$ be two nonempty subsets of a Banach space $(E,\|\cdot\|)$. Throughout this paper the following notations will be used:

$$
\begin{aligned}
d(X, Y) & =\inf \{\|x-y\|: x \in X, y \in Y\} ; \\
d(x, Y) & =\inf \{\|x-y\|: y \in Y\} \\
P_{X}(y) & =\{x \in X:\|x-y\|=d(y, Y)\} ; \\
X_{0} & =\left\{x \in X:\left\|x-y^{\prime}\right\|=d(X, Y), \text { for some } y^{\prime} \in Y\right\} ; \\
Y_{0} & =\left\{y \in Y:\left\|x^{\prime}-y\right\|=d(X, Y), \text { for some } x^{\prime} \in X\right\} .
\end{aligned}
$$

Definition 1 ([23]). A pair $(X, Y)$ of nonempty subsets of a normed vector space with $X_{0} \neq \varnothing$ is said to have the P-property if and and only if for any $x_{1}, x_{2} \in X_{0}$ and $y_{1}, y_{2} \in Y_{0}$,

$$
\left\{\begin{array}{l}
\left\|x_{1}-y_{1}\right\|=d(X, Y) \\
\left\|x_{2}-y_{2}\right\|=d(X, Y)
\end{array} \Longrightarrow\left\|x_{1}-x_{2}\right\|=\left\|y_{1}-y_{2}\right\| .\right.
$$

Lemma 1. Let $X$ and $Y$ be two nonempty closed bounded and convex subsets of a Banach space. If the pair $(X, Y)$ has the P-property, then both $X_{0}$ and $Y_{0}$ are closed bounded and convex sets.

Proof. To prove that $X_{0}$ is a closed set, take a sequence $\left\{x_{n}\right\} \subset X_{0}$, converging in the norm to some point $p \in X$. As $\left\{x_{n}\right\} \subset X_{0}$, one can associate a sequence $\left\{y_{n}\right\} \subset Y_{0}$, such that $\left\|x_{n}-y_{n}\right\|=d(X, Y)$ for all $n$. On the other hand, the $P$-property implies that $\left\|x_{n}-x_{m}\right\|=\left\|y_{n}-y_{m}\right\|$, for all $n$ and $m$. Thus, $\left\{y_{n}\right\} \subset Y_{0}$ is a Cauchy sequence, which converges to some $q \in Y$, since $Y$ is a closed set. Using now the inequality

$$
\|p-q\| \leq\left\|p-x_{n}\right\|+\left\|x_{n}-y_{n}\right\|+\left\|y_{n}-q\right\|,
$$

we conclude that $\|p-q\|=d(X, Y)$, meaning that $p \in X_{0}$. Thus $X_{0}$ is a closed set.

The set $X_{0}$ is bounded since $X$ is bounded.

To prove the convexity of the set $X_{0}$, take $x_{1}, x_{2} \in X_{0}$ and $\alpha \in[0,1]$. There exist $y_{1}, y_{2} \in Y_{0}$ such that

$$
\left\|x_{1}-y_{1}\right\|=d(X, Y)=\left\|x_{2}-y_{2}\right\| .
$$

From the convexity of the set $Y$ we get

$$
\begin{aligned}
\left\|\alpha x_{1}+(1-\alpha) x_{2}-\left(\alpha y_{1}+(1-\alpha) y_{2}\right)\right\| & \leq \alpha\left\|x_{1}-y_{1}\right\|+(1-\alpha)\left\|x_{2}-y_{2}\right\| \\
& =d(X, Y) .
\end{aligned}
$$

Thus $X_{0}$ is convex. The proof for $Y_{0}$ is similar. 
A Banach space $E$ is called uniformly convex (see for instance [24]) if, for each $\varepsilon \in(0,2]$, there exists $\delta>0$ such that for $x, y \in E$,

$$
\left.\begin{array}{l}
\|x\| \leq 1 \\
\|y\| \leq 1 \\
\|x-y\|>\varepsilon
\end{array}\right\} \Longrightarrow\left\|\frac{x+y}{2}\right\| \leq \delta .
$$

Let $C$ be a nonempty closed convex subset of a Banach space $E$. Given a bounded sequence $\left\{x_{n}\right\} \subset E$, setting, for a given $x \in E$,

$$
r\left(x,\left\{x_{n}\right\}\right)=\limsup _{n \rightarrow \infty}\left\|x-x_{n}\right\|
$$

one defines the asymptotic radius

$$
r\left(C,\left\{x_{n}\right\}\right)=\inf \left\{r\left(x,\left\{x_{n}\right\}\right): x \in C\right\},
$$

and, respectively, the asymptotic center

$$
A\left(C,\left\{x_{n}\right\}\right)=\left\{x \in C: r\left(x,\left\{x_{n}\right\}\right)=r\left(C,\left\{x_{n}\right\}\right)\right\},
$$

of the sequence $\left\{x_{n}\right\}$ with respect to $C$.

In a uniformly convex Banach space the asymptotic center of a bounded sequence consists of a single element [25]. In a paper published in 2011, García-Falset et al. introduced a new class of mappings satisfying the so-called condition (E) defined as follows.

Definition 2 ([5]). Let $C$ be a nonempty subset of a Banach space $(E,\|\cdot\|)$. We say that a mapping $T: C \rightarrow E$ satisfies the condition $\left(\mathrm{E}_{\mu}\right)$ if there exists $\mu \geq 1$ such that for all $x, y \in C$,

$$
\|x-T y\| \leq \mu\|x-T x\|+\|x-y\| .
$$

A mapping $T$ is said to satisfy the condition (E) whenever it satisfies $\left(\mathrm{E}_{\mu}\right)$ for some $\mu \geq 1$.

This condition is weaker than Suzuki's condition (C) for generalized nonexpansive mappings, a fact which follows from [4] Lemma 7. Recently Thakur et al. [12] have introduced a new iterative process, whose convergence to best proximity points of maps which satisfy the condition (E) we shall study. The iterative process, for a mapping satisfying the condition (E), is as follows.

$$
\left.\begin{array}{rl}
x_{1} & \in C \\
x_{n+1} & =T y_{n} \\
y_{n} & =T\left(\left(1-\alpha_{n}\right) x_{n}+\alpha_{n} z_{n}\right) \\
z_{n} & =\left(1-\beta_{n}\right) x_{n}+\beta_{n} T x_{n}
\end{array}\right\}
$$

for all $n \geq 1$, where $\left\{\alpha_{n}\right\}$ and $\left\{\beta_{n}\right\}$ are sequences in $(0,1)$.

The following lemma is the counterpart of Lemma 3.1 from [12], but for mappings satisfying the condition (E). We shall denote the set of fixed points of a mapping $T$ by $F(T)$.

Lemma 2. Let $C$ be a nonempty closed convex subset of a Banach space $(E,\|\cdot\|)$, and let $T: C \rightarrow C$ be a mapping satisfying the condition (E) such that $F(T) \neq \varnothing$. For arbitrary chosen $x_{1} \in C$, let the sequence $\left\{x_{n}\right\}$ be generated by the iterative process Equation (1). Then $\lim _{n \rightarrow \infty}\left\|x_{n}-p\right\|$ exists for any $p \in F(T)$.

Proof. Let $p \in F(T)$. As the mapping $T$ satisfies condition (E), we have

$$
\|T x-p\|=\|p-T x\| \leq \mu\|p-T p\|+\|x-p\|=\|x-p\|,
$$


for any $x \in C$.

Applying Equation (2) and using the triangle axiom, one has

$$
\begin{aligned}
\left\|z_{n}-p\right\| & =\left\|\left(1-\beta_{n}\right) x_{n}+\beta_{n} T x_{n}-p\right\| \\
& \leq\left(1-\beta_{n}\right)\left\|x_{n}-p\right\|+\beta_{n}\left\|T x_{n}-p\right\| \\
& \leq\left(1-\beta_{n}\right)\left\|x_{n}-p\right\|+\beta_{n}\left\|x_{n}-p\right\| \\
& =\left\|x_{n}-p\right\| .
\end{aligned}
$$

Similarly, using Equation (3), we get

$$
\begin{aligned}
\left\|y_{n}-p\right\| & =\left\|T\left(\left(1-\alpha_{n}\right) x_{n}+\alpha_{n} z_{n}\right)-p\right\| \\
& \leq\left\|\left(1-\alpha_{n}\right) x_{n}+\alpha_{n} z_{n}-p\right\| \\
& \leq\left(1-\alpha_{n}\right)\left\|x_{n}-p\right\|+\alpha_{n}\left\|z_{n}-p\right\| \\
& \leq\left(1-\alpha_{n}\right)\left\|x_{n}-p\right\|+\alpha_{n}\left\|x_{n}-p\right\| \\
& =\left\|x_{n}-p\right\| .
\end{aligned}
$$

Now Equations (2) and (4) yield

$$
\begin{aligned}
\left\|x_{n+1}-p\right\| & =\left\|T y_{n}-p\right\| \\
& \leq\left\|y_{n}-p\right\| \\
& \leq\left\|x_{n}-p\right\|,
\end{aligned}
$$

which means that the sequence $\left\{\left\|x_{n}-p\right\|\right\}$ is bounded and nonincreasing for any $p \in F(T)$. Thus, the limit $\lim _{n \rightarrow \infty}\left\|x_{n}-p\right\|$ exists.

The following theorem is an extension of Theorem 3.2 from [12] to the class of mappings satisfying condition (E). It is worth to compare it with Theorems 2 and 3 from [5]. We shall need the following technical lemma.

Lemma 3 ([26]). Suppose $(E,\|\cdot\|)$ is a uniformly convex Banach space and $\left\{t_{n}\right\}$ is a sequence bounded away from 0 and 1, i.e., $0<b \leq t_{n} \leq c<1$ for all $n \geq 1$. Let $\left\{x_{n}\right\}$ and $\left\{y_{n}\right\}$ be two sequences in $E$ such that $\limsup \left\|x_{n}\right\| \leq a$, limsup $\left\|y_{n}\right\| \leq a$ and $\limsup \left\|t_{n} x_{n}+\left(1-t_{n}\right) y_{n}\right\|=$ a hold for some $a \geq 0$. Then $\lim _{n \rightarrow \infty}\left\|x_{n}-y_{n}\right\|=0$.

Theorem 1. Let $C$ be a nonempty closed convex subset of a uniformly convex Banach space $E$ and let $T: C \rightarrow C$ be a mapping satisfying condition (E). Given a point $x_{1} \in C$, let the sequence $\left\{x_{n}\right\}, n \geq 1$, be generated by the iterative process Equation (1) with $\left\{\alpha_{n}\right\}$ and $\left\{\beta_{n}\right\}$ bounded away from 0 and 1 . Then $F(T) \neq \varnothing$ if and only if the sequence $\left\{x_{n}\right\}$ is bounded and $\lim _{n \rightarrow \infty}\left\|x_{n}-T x_{n}\right\|=0$ (i.e., $\left\{x_{n}\right\}$ is an approximate fixed point sequence).

Proof. Let $p \in F(T) \neq \varnothing$. According to Lemma 2 the limit

$$
a:=\lim _{n \rightarrow \infty}\left\|x_{n}-p\right\|
$$

exists and $\left\{x_{n}\right\}$ is a bounded sequence. Using Equations (2) and (3) respectively, we have

$$
\begin{aligned}
& \lim _{n \rightarrow \infty}\left\|z_{n}-p\right\| \leq \lim _{n \rightarrow \infty}\left\|x_{n}-p\right\|=a, \\
& \lim _{n \rightarrow \infty}\left\|T x_{n}-p\right\| \leq \lim _{n \rightarrow \infty}\left\|x_{n}-p\right\|=a .
\end{aligned}
$$


On the other hand, using Equations (2) and (5), together with the properties of the norm, we get

$$
\begin{aligned}
\left\|x_{n+1}-p\right\| & \leq\left\|y_{n}-p\right\| \\
& =\left\|T\left(\left(1-\alpha_{n}\right) x_{n}+\alpha_{n} z_{n}\right)-p\right\| \\
& \leq\left\|\left(1-\alpha_{n}\right) x_{n}+\alpha_{n} z_{n}-p\right\| \\
& \leq\left(1-\alpha_{n}\right)\left\|x_{n}-p\right\|+\alpha_{n}\left\|z_{n}-p\right\| \\
& =\left\|x_{n}-p\right\|-\alpha_{n}\left\|x_{n}-p\right\|+\alpha_{n}\left\|z_{n}-p\right\|,
\end{aligned}
$$

or, equivalently,

$$
\frac{\left\|x_{n+1}-p\right\|-\left\|x_{n}-p\right\|}{\alpha_{n}} \leq\left\|z_{n}-p\right\|-\left\|x_{n}-p\right\|
$$

Thus,

$$
\left\|x_{n+1}-p\right\|-\left\|x_{n}-p\right\| \leq\left\|z_{n}-p\right\|-\left\|x_{n}-p\right\|
$$

implying

$$
\left\|x_{n+1}-p\right\| \leq\left\|z_{n}-p\right\| .
$$

Whereas from Equation (2) we have that $\left\|z_{n}-p\right\| \leq\left\|x_{n}-p\right\|$ and thus

$$
a=\lim _{n \rightarrow \infty}\left\|z_{n}-p\right\| \text {. }
$$

It follows

$$
\lim _{n \rightarrow \infty}\left\|\beta_{n}\left(T x_{n}-p\right)+\left(1-\beta_{n}\right)\left(x_{n}-p\right)\right\|=\lim _{n \rightarrow \infty}\left\|z_{n}-p\right\|=a .
$$

Thus, the conditions of Lemma 3 are satisfied yielding $\lim _{n \rightarrow \infty}\left\|T x_{n}-x_{n}\right\|=0$.

Conversely, assume that $\left\{x_{n}\right\}$ is bounded and $\lim _{n \rightarrow \infty}\left\|T x_{n}-x_{n}\right\|=0$. Take a point $p \in A\left(C,\left\{X_{n}\right\}\right)$. Using the fact that the mapping $T$ satisfies the condition (E), we have

$$
\begin{aligned}
r\left(T p,\left\{x_{n}\right\}\right) & =\limsup _{n \rightarrow \infty}\left\|x_{n}-T p\right\| \\
& \leq \limsup _{n \rightarrow \infty}\left(\mu\left\|T x_{n}-x_{n}\right\|+\left\|x_{n}-p\right\|\right) \\
& =\limsup _{n \rightarrow \infty}\left\|x_{n}-p\right\| \\
& =r\left(p,\left\{x_{n}\right\}\right),
\end{aligned}
$$

which means that $T p$ lies in $A\left(C,\left\{X_{n}\right\}\right)$. On the other hand, since $E$ is uniformly convex, $A\left(C,\left\{X_{n}\right\}\right)$ is a singleton and hence $T p=p$.

Corollary 1. Let $C$ be a nonempty compact convex subset of a uniformly convex Banach space and let $\left\{x_{n}\right\}$ and $T$ be as in Theorem 1. If $F(T) \neq \varnothing$, then the sequence $\left\{x_{n}\right\}$ converges strongly to a fixed point of $T$.

Proof. If $F(T) \neq \varnothing$, then, according to Theorem $1 \lim _{n \rightarrow \infty}\left\|x_{n}-T x_{n}\right\|=0$. As $C$ is assumed to be compact, the sequence $\left\{x_{n}\right\}$ has a convergent subsequence $\left\{x_{n_{k}}\right\}$ to some point $p \in C$. Since the mapping $T$ satisfies the condition (E), for all $n \geq 1$ and some $\mu \geq 1$, we have

$$
\left\|x_{n_{k}}-T p\right\| \leq \mu\left\|x_{n_{k}}-T x_{n_{k}}\right\|+\left\|x_{n_{k}}-p\right\| .
$$

The uniqueness of the limit implies that $\left\{x_{n_{k}}\right\}$ converges strongly to $T p$, meaning that $T p \in F(T)$. On the other hand, according to Lemma 2, the limit $\lim _{n \rightarrow \infty}\left\|x_{n}-p\right\|$ exists which completes the proof. 


\section{Best Proximity Point Problem for (EP)-Mappings}

Let $X$ and $Y$ be two convex subsets in a Banach space. A non-self mapping $T: X \rightarrow Y$ is called nonexpansive if

$$
\|T x-T y\| \leq\|x-y\|, \text { for all } x, y \in X .
$$

Gabeleh [19] introduced a condition on mappings which is weaker than nonexpansiveness and which resembles Suzuki's condition (C), but in the context of non-self mappings.

Definition 3 ([19]). Let $(X, Y)$ be a pair of of nonempty subsets of a Banach space. A mapping $T: X \rightarrow Y$ is said to be proximal generalized nonexpansive if and only if for all $x, y, u, v \in X$ such that $\|u-T x\|=$ $d(X, Y)=\|v-T y\|$

$$
\frac{1}{2}(\|x-T x\|-d(X, Y)) \leq\|x-y\| \Longrightarrow\|u-v\| \leq\|x-y\| .
$$

The above definition can be widened by taking some $\lambda \in(0,1)$ instead of $1 / 2$.

Next we introduce a new condition on non-self mappings which can be seen as the analogue of the condition (E) introduced by García-Falset et al. [5] and which involves the metric projection.

Definition 4. Let $(X, Y)$ be a pair of of nonempty subsets of a Banach space $(E,\|\cdot\|)$ such that $X_{0} \neq \varnothing$ and denote by $P_{X_{0}}: E \rightarrow X_{0}$ the metric projection operator onto $X_{0}$. A mapping $T: X \rightarrow Y$ is said to satisfy the condition (EP) if and only if

$$
\left\|x-P_{X_{0}} T y\right\| \leq \mu\left\|x-P_{X_{0}} T x\right\|+\|x-y\|, \text { for all } x, y \in X .
$$

Proposition 1. Any proximal generalized nonexpansive mapping satisfies the condition (EP).

Proof. From Definition 3 it is clear that $u, v \in X_{0}$ (and hence $X_{0} \neq \varnothing$ ) and that $T x \in Y_{0}$. Also, from the definition of the metric projection we have $u=P_{X_{0}} T x$ and $v=P_{X_{0}} T y$. For any $\lambda \in(0,1)$ we have

$$
\begin{aligned}
\lambda(\|x-T x\|-d(X, Y)) & =\lambda\left(\|x-T x\|-\left\|P_{X_{0}} T x-T x\right\|\right) \\
& \leq \lambda\left\|x-P_{X_{0}} T x\right\| \\
& \leq\left\|x-P_{X_{0}} T x\right\| .
\end{aligned}
$$

Since the mapping $T$ is proximal generalized nonexpansive, it follows that

$$
\left\|P_{X_{0}} T x-P_{X_{0}} T y\right\| \leq\left\|x-P_{X_{0}} T x\right\| .
$$

On the other hand, the triangle inequality together the inequality Equation (11), yield

$$
\begin{aligned}
\left\|x-P_{X_{0}} T y\right\| & \leq\left\|x-P_{X_{0}} T x\right\|+\left\|P_{X_{0}} T x-P_{X_{0}} T y\right\| \\
& \leq 2\left\|x-P_{X_{0}} T x\right\|+\|x-y\|
\end{aligned}
$$

which means that the condition (EP) is satisfied for $\mu=2$.

Next, we adapt the iterative process Equation (1) for the case of non-self mappings using the metric projection as follows.

$$
\left.\begin{array}{rl}
x_{1} & \in X_{0} \\
x_{n+1} & =P_{X_{0}} T y_{n} \\
y_{n} & =P_{X_{0}} T\left(\left(1-\alpha_{n}\right) x_{n}+\alpha_{n} z_{n}\right) \\
z_{n} & =\left(1-\beta_{n}\right) x_{n}+\beta_{n} P_{X_{0}} T x_{n}
\end{array}\right\}
$$

for all $n \geq 1$, where $\left\{\alpha_{n}\right\}$ and $\left\{\beta_{n}\right\}$ are sequences bounded away from 0 and 1 . 
It is clear from Lemma 1 that the set $X_{0}$ is convex. Also, since the iterative process Equation (12) involves the metric projection onto $X_{0}$ and convex combinations of elements from $X_{0}$, it is clear that $\left\{x_{n}\right\} \subset X_{0}$.

The notion of approximate fixed point sequence has a natural extension in the context of best proximity point problem.

Definition 5 ([19]). Let $(X, Y)$ be a pair of nonempty sets of a Banach space and $T: X \rightarrow Y$ be a non-self mapping. A sequence $\left\{x_{n}\right\} \subset X$ is said to be an approximate best proximity point sequence for $T$ if and only if

$$
\lim _{n \rightarrow \infty}\left\|x_{n}-T x_{n}\right\|=d(X, Y) .
$$

Theorem 2. Let $(X, Y)$ be a pair of nonempty subsets of a Banach space $E$, where the pair has the P-property, $X$ is convex, $Y$ is closed and convex, and $X_{0} \neq \varnothing$. Suppose the mapping $T: X \rightarrow Y$ satisfies the condition (EP) with $T\left(X_{0}\right) \subseteq Y_{0}$ and let $\left\{x_{n}\right\}$ be the sequence generated by the iterative process (12). Then, the mapping $T$ has a best proximity point if and only if $\left\{x_{n}\right\}$ is bounded and $\lim _{n \rightarrow \infty}\left\|x_{n}-T x_{n}\right\|=d(X, Y)$.

Proof. According to Lemma 1 the set $X_{0}$ is closed and convex. If $p$ is a best proximity point for the mapping $T$, then $p$ is a fixed point for the mapping $P_{X_{0}} T: X_{0} \rightarrow X_{0}$, i.e., $F\left(P_{X_{0}} T\right) \neq \varnothing$. Thus, according to Theorem 1 , the sequence $\left\{x_{n}\right\}$ is bounded and $\lim _{n \rightarrow \infty}\left\|x_{n}-P_{X_{0}} T x_{n}\right\|=0$. Also, since $T\left(X_{0}\right) \subseteq Y_{0}$, we have that $\left\|P_{X_{0}} T x_{n}-T x_{n}\right\|=d(X, Y)$. Taking $n \rightarrow \infty$ in the inequality

$$
\left\|x_{n}-T x_{n}\right\| \leq\left\|x_{n}-P_{X_{0}} T x_{n}\right\|+\left\|P_{X_{0}} T x_{n}-T x_{n}\right\|, n \geq 1,
$$

yields $\lim _{n \rightarrow \infty}\left\|x_{n}-T x_{n}\right\|=d(X, Y)$.

Conversely, suppose that $\lim _{n \rightarrow \infty}\left\|x_{n}-T x_{n}\right\|=d(X, Y)$. Using this fact while passing to the limit in Equation (13) gives $\lim _{n \rightarrow \infty}\left\|x_{n}-P_{X_{0}} T x_{n}\right\|=0$. Since by assumption the sequence $\left\{x_{n}\right\}$ is bounded, according to Theorem 1, there exists $p \in X_{0}$ such that $P_{X_{0}} T p=p$, which means that $\|p-T p\|=d(X, Y)$.

Corollary 2. Let $(X, Y), T$, and $\left\{x_{n}\right\}$ be as in Theorem 2 and suppose additionally that $X$ is compact. If $F\left(P_{X_{0}} T\right) \neq \varnothing$, then the sequence $\left\{x_{n}\right\}$ generated by the iterative process (12) converges strongly to a best proximity point of $T$.

Proof. Since $X$ is compact, the sequence $\left\{x_{n}\right\}$ has a subsequence $\left\{x_{n_{k}}\right\}$ converging strongly to some point $z \in X$. Also, since $F\left(P_{X_{0}} T\right) \neq \varnothing$, we have that $\lim _{n \rightarrow \infty}\left\|x_{n}-P_{X_{0}} T x_{n}\right\|=0$. Letting $k \rightarrow \infty$ in the relation

$$
\left\|x_{n_{k}}-P_{X_{0}} T z\right\| \leq \mu\left\|x_{n_{k}}-P_{X_{0}} T x_{n_{k}}\right\|+\left\|x_{n_{k}}-z\right\|,
$$

we obtain that $x_{n_{k}}$ converges strongly to $P_{X_{0}} T z$ and by the uniqueness of the limit we have $z=P_{X_{0}} T z$, i.e., $z \in F\left(P_{X_{0}} T\right)$. Applying now Lemma 2 yields the conclusion.

\section{Strong Convergence via a CQ-Type Algorithm}

In this section we introduce an algorithm which is a hybrid between the iterative process (12) and the CQ algorithm introduced by Nakajo and Takahashi [20]. The main outcome is the strong convergence of the resulting sequence. Before dealing with the main result, let us establish the following preliminaries.

Let $H$ be a real Hilbert and denote the inner product by $\langle\cdot, \cdot\rangle$ and, respectively, the norm by $\|\cdot\|$. Let $X$ and $Y$ be nonempty closed and convex subsets of $H$. Given a mapping $T: X \rightarrow Y$, we denote the set of its best proximity points by $X_{T}$, i.e.,

$$
X_{T}=\{x \in X: d(x, T x)=d(X, Y)\} .
$$


Clearly $X_{T} \subseteq X_{0}$ (for details, one can see [27]).

For a sequence $\left\{x_{n}\right\} \subset X$ let

$$
w_{\omega}\left(\left\{x_{n}\right\}\right)=\left\{x: \exists\left\{x_{n_{k}}\right\} \subset\left\{x_{n}\right\}, x_{n_{k}} \rightarrow x\right\},
$$

where $\rightarrow$ denotes the weak convergence, be the weak $\omega$-limit set.

Lemma 4 ([28]). Let $K$ be a closed and convex subset of a real Hilbert space $H$ and let $P_{K}$ be the metric projection from $H$ onto $K$. Then, given $x \in H$ and $z \in K$,

$$
z=P_{K} x \text { if and only if }\langle x-z, y-z\rangle \leq 0,
$$

for all $y \in K$.

Lemma 5 ([28]). Let $K$ be a closed and convex subset of a real Hilbert space $H$. Let $\left\{x_{n}\right\}$ be a sequence in $H$ and let $x \in H$. Let $q=P_{K} x$. If $\left\{x_{n}\right\}$ is such that $w_{\omega}\left(\left\{x_{n}\right\}\right) \subset K$ and satisfies the condition

$$
\left\|x_{n}-x\right\| \leq\|x-q\|, \text { for all } n \in \mathbb{N},
$$

then $x_{n} \rightarrow q$.

A Banach space $(E,\|\cdot\|)$ is said to have the Opial property if, for every sequence $\left\{x_{n}\right\} \subset E$ such that $x_{n} \rightarrow z$, the inequality

$$
\liminf _{n \rightarrow \infty}\left\|x_{n}-z\right\|<\liminf _{n \rightarrow \infty}\left\|x_{n}-y\right\|
$$

holds whenever $y \neq z$. It is worth mentioning that any Hilbert space has the Opial property (for a proof, please see [29]).

Lemma 6 (Theorem 1, [5]). Let $C$ be a nonempty subset of a Banach space $E$ and let $T: C \rightarrow E$ be a given mapping. If

a) there exists a sequence $\left\{x_{n}\right\} \subset C$ such that $\left\|x_{n}-T x_{n}\right\| \rightarrow 0$ and $z_{n} \rightarrow z$,

b) T satisfies the condition (E) on $C$,

c) $(E,\|\cdot\|)$ has the Opial property,

then $T z=z$.

Consider now the following algorithm:

$$
\begin{aligned}
& x_{0} \in X_{0} \text { arbitrary, } \\
& z_{n}=\left(1-\beta_{n}\right) x_{n}+\beta_{n} P_{X_{0}} T x_{n}, \\
& y_{n}=P_{X_{0}} T\left(\left(1-\alpha_{n}\right) x_{n}+\alpha_{n} z_{n}\right), \\
& w_{n}=P_{X_{0}} T y_{n}, \\
& Q_{n}=\left\{u \in X_{0}:\left\langle x_{n}-u, x_{n}-x_{0}\right\rangle \leq 0\right\} ; \\
& C_{n}=\left\{u \in X_{0}: \max \left\{\left\|w_{n}-u\right\|,\left\|y_{n}-u\right\|,\left\|z_{n}-u\right\|\right\} \leq\left\|x_{n}-u\right\|\right\}, \\
& x_{n+1}=P_{\left(C_{n} \cap Q_{n}\right)} x_{0},
\end{aligned}
$$

where $\left\{\alpha_{n}\right\}$ and $\left\{\beta_{n}\right\}$ are real sequences bounded away from 0 and 1 .

Clearly the projection is well defined since the set $X_{0}$ is closed and convex, according to Lemma 1.

Theorem 3. Let $(X, Y)$ be a pair of nonempty closed and convex subsets of a real Hilbert space, and suppose the pair has the P-property. Let $T: X \rightarrow Y$ be a mapping which satisfies the condition $(\mathrm{EP})$ such that $X_{T}$ is a nonempty convex subset of $X_{0}$. Then, the sequence $\left\{x_{n}\right\}$, generated by the algorithm (12), converges to a best 
proximity point. In particular, it converges to $p$, where $p=P_{X_{T}}\left(x_{0}\right)$. Moreover, the same holds true for the sequences $\left\{w_{n}\right\},\left\{y_{n}\right\}$ and $\left\{z_{n}\right\}$.

Proof. Let $x_{0} \in X_{0}$. Clearly the sets $Q_{n}$ and $C_{n}$ respectively, are closed and convex subsets of $X$. Let us prove that $X_{T} \subset C_{n} \cap Q_{n}$.

Let $z \in X_{T}$. Clearly, $d(z, T z)=d(X, Y)$, i.e., $d\left(z, P_{X_{0}} T z\right)=0$. Keeping in mind that the mapping $T$ satisfies the condition (EP), we have

$$
\begin{aligned}
\left\|z_{n}-z\right\| & =\left\|\left(1-\beta_{n}\right) x_{n}+\beta_{n} P_{X_{0}} T x_{n}-z\right\| \\
& \leq\left(1-\beta_{n}\right)\left\|x_{n}-z\right\|+\beta_{n}\left\|P_{X_{0}} T x_{n}-z\right\| \\
& \leq\left(1-\beta_{n}\right)\left\|x_{n}-z\right\|+\beta_{n}\left(\mu\left\|P_{X_{0}} T z-z\right\|+\left\|x_{n}-z\right\|\right) \\
& \leq\left\|x_{n}-z\right\| .
\end{aligned}
$$

Similarly, we get the inequality

$$
\begin{aligned}
\left\|y_{n}-z\right\| & =\left\|P_{X_{0}} T\left(\left(1-\alpha_{n}\right) x_{n}+\alpha_{n} z_{n}\right)-z\right\| \\
& \leq \mu\left\|P_{X_{0}} T z-z\right\|+\left\|\left(1-\alpha_{n}\right) x_{n}+\alpha_{n} z_{n}-z\right\| \\
& \leq\left(1-\alpha_{n}\right)\left\|z_{n}-z\right\|+\alpha_{n}\left\|z_{n}-z\right\| \\
& =\left\|z_{n}-z\right\|,
\end{aligned}
$$

and, respectively,

$$
\begin{aligned}
\left\|w_{n}-z\right\| & =\left\|P_{X_{0}} T\left(P_{X_{0}} T\left(\left(1-\alpha_{n}\right) x_{n}+\alpha_{n} z_{n}\right)\right)-z\right\| \\
& \leq \mu\left\|P_{X_{0}} T z-z\right\|+\left\|P_{X_{0}} T\left(\left(1-\alpha_{n}\right) x_{n}+\alpha_{n} z_{n}\right)-z\right\| \\
& \leq \mu\left\|P_{X_{0}} T z-z\right\|+\left\|\left(1-\alpha_{n}\right) x_{n}+\alpha_{n} z_{n}-z\right\| \\
& \leq\left(1-\alpha_{n}\right)\left\|z_{n}-z\right\|+\alpha_{n}\left\|z_{n}-z\right\| \\
& =\left\|z_{n}-z\right\| .
\end{aligned}
$$

Hence, $z \in C_{n}$, i.e., $X_{T} \subset C_{n}$.

The inclusion $X_{T} \subset Q_{n}$ follows by induction. Indeed, it is clear from the definition that $Q_{0}=X_{0}$ and that $X_{T} \subset X_{0}$, respectively. Assume $X_{T} \subset Q_{n}$. As $C_{n}$ and $Q_{n}$ are closed and convex sets, for $x_{n+1}=P_{C_{n} \cap Q_{n}}\left(x_{0}\right)$, according to Lemma 4 , one has $\left\langle x_{n+1}-z, x_{n+1}-x_{0}\right\rangle \leq 0$ for all $z \in C_{n} \cap Q_{n}$. Using again the definition of the set $Q_{n}$ and noticing that $X_{T} \subset C_{n} \cap Q_{n}$ yields $X_{T} \subset Q_{n+1}$, which completes the induction.

Let $p=P_{X_{T}}\left(x_{0}\right)$. Since $X_{T} \subset C_{n} \cap Q_{n}$ and $x_{n+1}=P_{C_{n} \cap Q_{n}}\left(x_{0}\right)$, we have

$$
\left\|x_{n+1}-x_{0}\right\| \leq\left\|p-x_{0}\right\|
$$

which also means that the sequence $\left\{x_{n}\right\}$ is bounded.

Since $x_{n+1} \in Q_{n}$, we obtain

$$
\begin{aligned}
\left\|x_{n+1}-x_{n}\right\|^{2} & =\left\langle x_{n+1}-x_{n}, x_{n+1}-x_{n}\right\rangle \\
& =\left\langle x_{n+1}-x_{0}+x_{0}-x_{n}, x_{n+1}-x_{0}+x_{0}-x_{n}\right\rangle \\
& =\left\|x_{n+1}-x_{0}\right\|^{2}-\left\|x_{n}-x_{0}\right\|^{2}-2\left\langle x_{n+1}-x_{n}, x_{n}-x_{0}\right\rangle \\
& \leq\left\|x_{n+1}-x_{0}\right\|^{2}-\left\|x_{n}-x_{0}\right\|^{2}
\end{aligned}
$$

implying $\left\|x_{n+1}-x_{n}\right\| \rightarrow 0$ for $n \rightarrow \infty$.

On the other hand, the triangle axiom and the definition of $C_{n}$ yield

$$
\begin{aligned}
\left\|z_{n}-x_{n}\right\| & \leq\left\|z_{n}-x_{n+1}\right\|+\left\|x_{n+1}-x_{n}\right\| \\
& \leq\left\|x_{n}-x_{n+1}\right\|+\left\|x_{n+1}-x_{n}\right\|
\end{aligned}
$$

and thus $\left\|z_{n}-x_{n}\right\| \rightarrow 0$ for $n \rightarrow \infty$. 
Noticing that $\left\|z_{n}-x_{n}\right\|=\beta_{n}\left\|P_{X_{0}} T x_{n}-x_{n}\right\|$, it follows that $\left\|P_{X_{0}} T x_{n}-x_{n}\right\| \rightarrow 0$ as $n \rightarrow \infty$, since the sequence $\left\{\beta_{n}\right\}$ is bounded away from 0 and 1 .

Consider now the mapping $P_{X_{0}} T: X_{0} \rightarrow X_{0}$, which clearly satisfies the condition (E). The set of its fixed points is the set $X_{T}$. Recalling that any Hilbert space has the Opial property, while Applying Lemma 6, yields the inclusion $w_{\omega}\left(\left\{x_{n}\right\}\right) \subset X_{T}$. This fact, together with inequality Equation (18), according to Lemma 5, provides the strong convergence of the sequence $\left\{x_{n}\right\}$ to the point $p=P_{X_{T}}\left(x_{0}\right)$.

Turning now to the strong convergence of the other sequences, we have

$$
\begin{aligned}
\left\|w_{n}-x_{n}\right\| & \leq\left\|w_{n}-x_{n+1}\right\|+\left\|x_{n+1}-x_{n}\right\| \\
& \leq\left\|x_{n}-x_{n+1}\right\|+\left\|x_{n+1}-x_{n}\right\|
\end{aligned}
$$

and thus $\left\|w_{n}-x_{n}\right\| \rightarrow 0$. Similarly, one obtains $\left\|y_{n}-x_{n}\right\| \rightarrow 0$.

Lastly, the strong convergence of the sequences $\left\{w_{n}\right\},\left\{y_{n}\right\}$, and $\left\{z_{n}\right\}$ follow by taking $n \rightarrow \infty$ in the inequalities

$$
\begin{aligned}
& \left\|w_{n}-p\right\| \leq\left\|w_{n}-x_{n}\right\|+\left\|x_{n}-p\right\|, \\
& \left\|y_{n}-p\right\| \leq\left\|y_{n}-x_{n}\right\|+\left\|x_{n}-p\right\|, \\
& \left\|z_{n}-p\right\| \leq\left\|z_{n}-x_{n}\right\|+\left\|x_{n}-p\right\| .
\end{aligned}
$$

\section{Conclusions}

The starting point of our study in this paper has two main ingredients. One of them is the iterative process introduced by Thakur et al. [12], for Suzuki generalized nonexpansive mappings. The other is a class of mappings satisfying the condition (E), introduced by García-Falset et al. and which is even larger. We firstly extended the main results from [12] to the case of mappings satisfying condition (E). Afterwards, we have progressed to the setting of best proximity point problem, which is a generalization of the fixed point problem, by introducing a new class of non-self mappings. These generalize the class of proximal generalized nonexpansive mappings introduced by Gabeleh [19]. We have also adapted the iterative process from [12] to the setting of non-self mappings, using the metric projection, and have studied the convergence of the resulting iterative sequence. In the last part, we have constructed a CQ-type algorithm [20] for the iterative process under consideration and have proved the strong convergence of the resulting sequence to a best proximity point for mappings satisfying the condition (EP).

Author Contributions: conceptualization, H.H. and T.T.; writing-original draft preparation, T.T.; writing-review and editing, H.H.

Funding: This research received no external funding.

Conflicts of Interest: The authors declare no conflict of interest.

\section{References}

1. Kirk, W.A. A fixed point theorem for mappings which do not increase distances. Am. Math. Mon. 1965, 72, 1004-1006. [CrossRef]

2. Browder, F.E. Nonexpansive nonlinear operators in a Banach space. Proc. Natl. Acad. Sci. USA 1965, 54, 1041-1044. [CrossRef] [PubMed]

3. Göhde, D. Zum Prinzip der kontraktiven Abbildung. Math. Nachr. 1965, 30, 251-258. [CrossRef]

4. Suzuki, T. Fixed point theorems and convergence theorems for some generalized nonexpansive mappings. J. Math. Anal. Appl. 2008, 340, 1088-1095. [CrossRef]

5. García-Falset, J.; Llorens-Fuster, E.; Suzuki, T. Fixed point theory for a class of generalized nonexpansive mappings. J. Math. Anal. Appl. 2011, 375, 185-195. [CrossRef]

6. Mann, W.R. Mean value methods in iteration. Proc. Am. Math. Soc. 1953, 4, 506-510. [CrossRef]

7. Ishikawa, S. Fixed points by a new iteration method. Proc. Am. Math. Soc. 1974, 44, 147-150. [CrossRef] 
8. Noor, M.A. New approximation schemes for general variational inequalities. J. Math. Anal. Appl. 2000, 251, 217-229. [CrossRef]

9. Agarwal, R.P.; O'Regan, D.; Sahu, D.R. Iterative construction of fixed points of nearly asymptotically nonexpansive mappings in Banach spaces. Fixed Point Theory Appl. 2010, 8, 457935.

10. Abbas, M.; Nazir, T. A new faster iteration process applied to constrained minimization and feasibility problems. Mat. Vesn. 2014, 66, 223-234.

11. Sintunavarat, W.; Pitea, A. On a new iteration scheme for numerical reckoning fixed points of Berinde mappings with convergence analysis. J. Nonlinear Sci. Appl. 2016, 9, 2553-2562. [CrossRef]

12. Thakur, B.S.; Thakur, D.; Postolache, M. A new iterative scheme for numerical reckoning fixed points of Suzuki's generalized nonexpansive mappings. Appl. Math. Comput. 2016, 275, 147-155. [CrossRef]

13. Thakur, B.S.; Thakur, D.; Postolache, M. A new iteration scheme for approximating fixed points of nonexpansive mappings. Filomat 2016, 30, 2711-2720. [CrossRef]

14. Thakur, D.; Thakur, B.S.; Postolache, M. New iteration scheme for numerical reckoning fixed points of nonexpansive mappings. J. Inequal. Appl. 2014, 2014, 328. [CrossRef]

15. Fan, K. Extensions of two fixed point theorems of F.E. Browder. Math. Z. 1969, 122, 234-240. [CrossRef]

16. Reich, S. Approximate selections, best approximations, fixed points and invariant sets. J. Math. Anal. Appl. 1978, 62, 104-113. [CrossRef]

17. Seghal, V.M.; Singh, S.P. A generalization of multifunctions of Fans best approximation theorem. Proc. Am. Math. Soc. 1988, 102, 534-537.

18. Naraghirad, E. Bregman best proximity points for Bregman asymptotic cyclic contraction mappings in Banach spaces. J. Nonlinear Var. Anal. 2019, 3, 27-44.

19. Gabeleh, M. Best proximity point theorem via proximal non-self mappings. J. Optim. Theory Appl. 2015, 164, 565-576. [CrossRef]

20. Nakajo, K.; Takahashi, W. Strong convergence theorems for nonexpansive mappings and nonexpansive semigroups. J. Math. Anal. Appl. 2003, 279, 372-379. [CrossRef]

21. Takahashi, W. Weak and strong convergence theorems for families of nonlinear and nonself mappings in Hilbert spaces. J. Nonlinear Var. Anal. 2017, 1, 1-23.

22. Jacob, G.K.; Postolache, M.; Marudai, M.; Raja, V. Norm convergence iterations for best proximity points of non-self non-expansive mappings. UPB Sci. Bull. Seri. A 2017, 79, 49-56.

23. Sankar Raj, V. A best proximity point theorem for weakly contractive non-self mappings. Nonlinear Anal. 2011, 74, 4804-4808. [CrossRef]

24. Goebel, K.; Kirk, W.A. Topics in Metric Fixed Point Theory; Cambridge University Press: Cambridge, UK, 1990.

25. Edelstein, M. The construction of an asymptotic center with a fixed-point property. Bull. Am. Math. Soc. 1972, 78, 206-208. [CrossRef]

26. Schu, J. Weak and strong convergence to fixed points of asymptotically nonexpansive mppings. Bull. Aust. Math. Soc. 1991, 43, 153-159. [CrossRef]

27. Shatanawi, W.; Pitea, A. Best proximity point and best proximity coupled point in a complete metric space with (P)-property. Filomat 2015, 29, 63-74. [CrossRef]

28. Martinez-Yanes, C.; Xu, H.K. Strong convergence of the CQ method for fixed point iteration processes. Nonlinear Anal. 2006, 64, 2400-2411. [CrossRef]

29. Opial, Z. Weak convergence of the sequence of successive approximations for nonexpansive mappings. Bull. Am. Math. Soc. 1967, 73, 591-597. [CrossRef]

(C) 2019 by the authors. Licensee MDPI, Basel, Switzerland. This article is an open access article distributed under the terms and conditions of the Creative Commons Attribution (CC BY) license (http:/ / creativecommons.org/licenses/by/4.0/). 